慢性閉塞性肺疾患（COPD）患者における呼吸リハビリ

$$
\text { テーションの肺機能及び運動耐容能への影響 }
$$

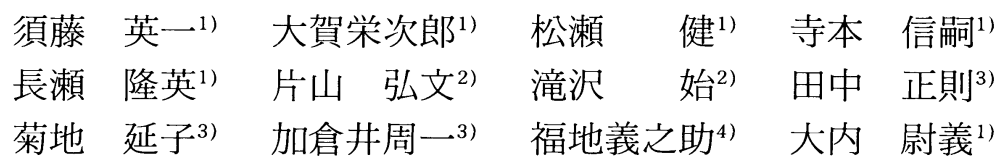

\begin{abstract}
<要 約 > 慢性閉塞性肺疾患（chronic obstructive pulmonary disease：COPD）症例13例（平均年 齢70.3 2.7 歳) 対象に呼吸法訓練に吸気筋訓練を取り入れた呼吸リハビリテーションを施行し, その 効果を検討した。呼吸法訓練は全身リラクセーション, 腹式呼吸, 口すぼめ呼吸を最初は 1 回/週から個々 の達成度に合わせて 6 週，12週まで指導した。吸気筋訓練は吸気筋訓練器 (Threshold ${ }^{\circledR}$ ) を用い, 抵抗 圧レベルをロ腔内最大吸気圧 (PImax) の15\%に設定し，15分間，2 回/日施行した。13例を呼吸法訓練 と吸気筋訓練を同時に施行した (A) 群と呼吸法訓練のみの (B) 群とに分け，12週後に効果を検討した。 $\mathrm{A}$ 群では機能的残気量 $(\mathrm{FRC})$ が $4.3 \pm 0.4$ (L) から $3.9 \pm 0.4$ (L) に $(\mathrm{p}<0.01)$, 最大呼気流速 $(\mathrm{V} \mathrm{p})$

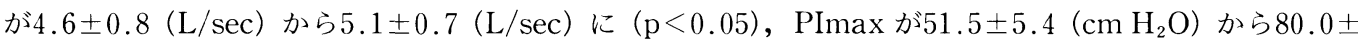
$7.0\left(\mathrm{~cm} \mathrm{H}_{2} \mathrm{O}\right)$ に $(\mathrm{p}<0.02)$ それぞれ改善していたが，B群では変化を認めなかった．10分間歩行距離 では A 群で変化を認めなかったが, B 群では有意に改善がみられた. 老年者の COPD 症例においても呼 吸法訓練に吸気筋訓練を加えた呼吸リハビリテーションにより, 肺機能や吸気筋力が改善することが示 されたが，運動耐容能には影響を与えないものと考えられた。
\end{abstract}

Key words : 慢性閉塞性肺疾患 (chronic obstructive pulmonary disease : COPD), 呼吸リハビリテー ション, 吸気筋訓練, 呼吸法訓練, 口腔内最大吸気圧 (PImax), 口腔内最大呼気圧 (PEmax)，10分間歩行距離

（日老医誌 $1997 ； 34 ： 929-934 ）$

\section{緒言}

慢性閉塞性肺疾患 (chronic obstructive pulmonary disease : 以下 COPD) の病態や予後の改善が, 呼吸 法・呼吸筋訓練によって達成されるか否かはこれまで

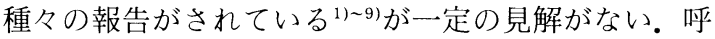
吸筋も他の骨格筋と同様に訓練によって機能が改善さ れるものとされているが, COPD 症例の吸気筋訓練が 運動耐容能に及ぼす影響に関しては報告が異なる。今 回我々は COPD 症例13例 (平均年齢70.3土2.7歳) を対

1) E. Sudo, E. Ohga, T. Matsuse, S. Teramoto, T. Nagase, Y. Ouchi：東京大学医学部老年病学

2) H. Katayama, H. Takizawa : 同 検査部

3) M. Tanaka, N. Kikuchi, S. Kakurai：同リハビ リテーション部

4) Y. Fukuchi：順天堂大学呼吸器内科

受付日：1997.2.25，採用日：1997.8.28
象に, 老年者の COPD 症例に定量的な吸気負荷と従来 よりの呼吸法の教育を組み合わせた呼吸りハビリテー ション (以下呼吸リハビリ) により，肺機能や運動能 力にどのような効果を認めるかを検討した.

\section{対象}

以下の条件を満たす COPD 患者を対象とした。（1） 持続する息切れを主訴とし, 喘息発作の既往がなく, （2）画像診断上 COPD に合致する所見（胸部 X 線上 肺過膨脹所見，胸部 CT にて low attenuation area の 存在）があり，(3) 呼吸機能検查上 $\mathrm{FEV}_{1.0} \%$ （1 秒 率) $<55 \%, \% \mathrm{DLco}$ (拡散能力) $<50(\%), \mathrm{RV}$ (残気 量) /TLC (総肺気量) $\times 100 \%$ (残気率) $>40 \%$ を満た し, 状態の安定している症例13例 (平均年歯70.3 2 .7 歳）を対象とした。この13例で呼吸法訓練と吸気筋訓 練を同時に施行した（A）群，呼吸法訓練のみの（B) 群に分類した（表 1 ）。呼吸困難度は全例 Hugh-Jones 
分類でIII度であった。またリハビリテーション期間中 は全例, 治療は不変とし禁煙とした。(A) 群, (B) 群 の間で明らかな治療内容（気管支拡張剤, テオフィリ ン，去痰剤など）の相違は認めなかった。

\section{方 法}

吸気筋訓練は吸気筋訓練器 (Threshold ${ }^{\circledR}$, Healthscan Products Inc., Cedar Grove, NJ, USA）を用 い, 抵抗圧レベルを個々の症例の口腔内最大吸気圧 (PImax）の15\%に設定し，1 回15分間，2 回/日施行 した。呼吸法訓練は従来より施行されている全身のリ ラクセーション, 腹式呼吸, 口すぼめ呼吸を習得させ た.リハビリ期間は 1 回/週, 約 1 時間を 12 週間実施し, 訓練開始前, 開始 6 週後, 12 週後に評価した. 評価項 目は呼吸機能（スパイロメトリー, 肺気量分画, フ ロー・ボリュウム曲線, 拡散能力), PImax, 口腔内最 大呼気圧 (PEmax), 10分間歩行距離である. VC (肺 活量), $\mathrm{FEV}_{1.0}$ (一秒量) の測定は CHESTAC-55V (チェストエム・アイ K.K.) を用い, FRC (機能的残 気量）は He ガス希釈法（閉鎖回路法）で測定した。 PImax, PEmax の測定は Black と Hyatt の方法 ${ }^{10} に$ 拠り測定し, PImaxはFRCレベルから, PEmaxは TLC (総肺気量) レベルからそれぞれ測定した。10分 間歩行距離測定は Dekhuyzen ら ${ }^{11}$ の方法に従った。 統計処理は群間比較はANOVAにより,リハビリ前 後の比較は paired-t 検定で行った。

\section{結果}

呼吸リハビリテーション前の A, B 2 群間に年齢, 身長, 体重, 呼吸機能に有意な差を認めなかった（表
1).

呼吸機能検査は, 呼吸リハビリ後で, A 群において

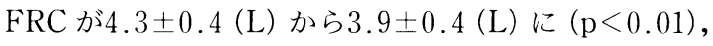
最大呼気流速 $(\mathrm{V} p)$ が $4.6 \pm 0.8(\mathrm{~L})$ から $5.1 \pm 0.7(\mathrm{~L})$

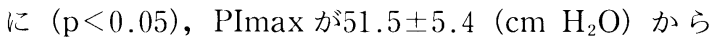
$80.0 \pm 7.0\left(\mathrm{~cm} \mathrm{H}_{2} \mathrm{O}\right)$ に $(\mathrm{p}<0.02)$ それぞれ改善して いた (表 2 )。呼吸筋訓練を含んでいない B 群ではこれ らの変化を認めなかった．図1はリハビリ前からの PImax の変化を, 変化率で表したものであり, 6 週後 より有意に増加していた。PEmax は A 群で前 $81.1 \pm$ $4.9\left(\mathrm{~cm} \mathrm{H}_{2} \mathrm{O}\right)$ から12週の後100.1土9.0 ( $\left.\mathrm{cm} \mathrm{H}_{2} \mathrm{O}\right)$ までの増加を認めたが, 有意差はなかった（図 2 ).

10分間歩行距離測定では A 群で変化を認めなかっ たが，B 群では前 $630 \pm 67(\mathrm{~m})$ から後 $707 \pm 62(\mathrm{~m})$ と 有意に改善がみられた（図 3 )。

FRCがA 群でリハビリ後低下していたが，その改 善はどの因子による影響を受けているかを検討するた めに $\Delta \mathrm{FRC}$ と $\Delta \mathrm{ERV}$ (予備呼気量), $\Delta \mathrm{FRC}$ と $\Delta \mathrm{RV}$

表 1 対象症例

\begin{tabular}{lr|c|c}
\hline & & $\begin{array}{c}\text { Group A } \\
(\mathrm{n}=7)\end{array}$ & $\begin{array}{c}\text { Group B } \\
(\mathrm{n}=6)\end{array}$ \\
\hline Age & (year) & $72.6 \pm 4.0$ & $67.6 \pm 3.5$ \\
Height & $(\mathrm{cm})$ & $162 \pm 2.5$ & $160.7 \pm 2.4$ \\
Body weight & $(\mathrm{kg})$ & $59.0 \pm 3.5$ & $54.9 \pm 2.9$ \\
VC & $(\mathrm{L})$ & $2.91 \pm 0.4$ & $2.59 \pm 0.23$ \\
FEV 1.0 & $(\mathrm{L})$ & $1.04 \pm 0.13$ & $1.03 \pm 0.14$ \\
FEV1.0/FVC & $(\%)$ & $43.2 \pm 4.4$ & $43.5 \pm 4.1$ \\
$\dot{V}_{p}$ & $(\mathrm{~L} / \mathrm{sec})$ & $4.55 \pm 0.78$ & $3.35 \pm 0.24$ \\
FRC & $(\mathrm{L})$ & $4.25 \pm 0.42$ & $3.58 \pm 0.48$ \\
RV & $(\mathrm{L})$ & $3.27 \pm 0.28$ & $2.86 \pm 0.45$ \\
\hline \multicolumn{3}{|c}{}
\end{tabular}

表 2 呼吸リハビリテーション前後の呼吸機能検查結果の比較

\begin{tabular}{l|c|c|c|c}
\hline \multirow{2}{*}{ Values } & \multicolumn{2}{|c|}{ Group (A) } & \multicolumn{2}{c}{ Group (B) } \\
\cline { 2 - 5 } & Baseline & At 12 weeks & Baseline & At 12 weeks \\
\hline $\mathrm{VC}, \mathrm{L}$ & $2.9 \pm 0.4$ & $3.1 \pm 0.3$ & $2.6 \pm 0.2$ & $2.7 \pm 0.3$ \\
$\% \mathrm{VC}$ & $89.2 \pm 10.4$ & $94.8 \pm 8.4$ & $83.0 \pm 4.0$ & $87.8 \pm 7.4$ \\
$\mathrm{FEV} \mathrm{H}_{1.0}$ & $1.04 \pm 0.13$ & $1.05 \pm 0.13$ & $1.03 \pm 0.14$ & $1.03 \pm 0.15$ \\
$\mathrm{FEV}{ }_{1.0} " \circ$ & $43.2 \pm 4.4$ & $44.2 \pm 4.2$ & $43.5 \pm 4.1$ & $42.4 \pm 5.2$ \\
$\dot{\mathrm{V}}_{\mathrm{p}, \mathrm{L} / \mathrm{sec}}$ & $4.6 \pm 0.8$ & $5.1 \pm 0.7 \dagger$ & $3.4 \pm 0.2$ & $3.8 \pm 0.6$ \\
$\mathrm{FRC}, \mathrm{L}$ & $4.3 \pm 0.4$ & $3.9 \pm 0.4 \S$ & $3.6 \pm 0.5$ & $3.7 \pm 0.5$ \\
\hline
\end{tabular}

值は mean \pm SEM. Group (A) は呼吸法訓練に吸気筋訓練を加えた群, Group (B)は呼 吸法訓練群. $\mathrm{VC}=$ vital capacity $; \mathrm{FEV}_{1.0}=$ forced expiratory volume in one second $\dot{\mathrm{V}} \mathrm{p}=$ maximal peak flow; $\mathrm{FRC}=$ functional residual capacity.

$\dagger: p<0.05$ in comparison with baseline value. $\S: p<0.01$ in comparison with baseline value. 


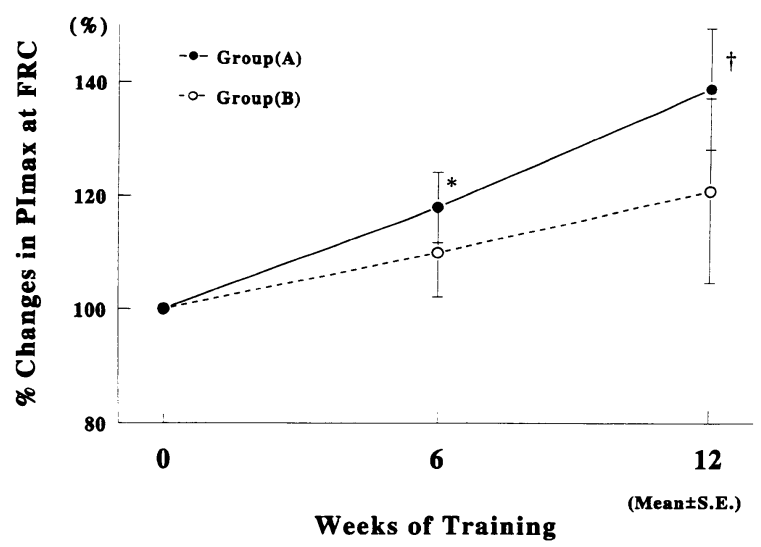

図 1 呼吸リハビリテーションによるPImax の変化 率の推移を示す。値は mean士SEM. Group (A) は 呼吸法訓練に吸気筋訓練を加えた群, Group (B) は 呼吸法訓練群. PImax $=$ maximal inspiratory pressure. ${ }^{*}: p<0.05$ compared to baseline. $\dagger: p<$ 0.02 compared to baseline.

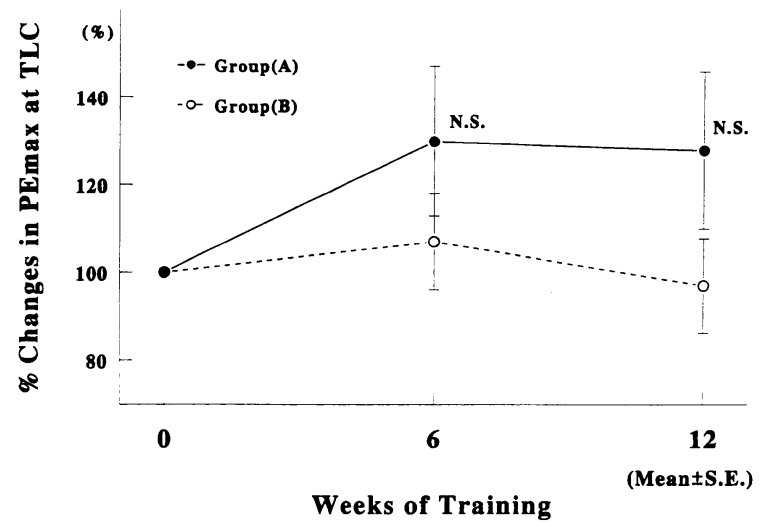

図2 呼吸リハビリテーションによるPEmax の変化 率の推移を示す。結果は mean \pm SEM. Group (A) は呼吸法訓練に吸気筋訓練を加えた群, Group (B) は呼吸法訓練群。訓練前後で 2 群とも有意差を認め なかった. PEmax = maximal expiratory pressure. N.S. $=$ no significance.

(残気量) のそれぞれの相関関係を検討したところ, $\triangle \mathrm{FRC}$ は $\Delta \mathrm{RV}$ と有意な相関関係が得られた (図 4 ).

\section{考察}

Leith と Bradley が健常人を対象に吸気筋訓練の有 用性を報告をして以来 ${ }^{1)}$, COPD 症例を対象に吸気筋 訓練が試みられてきている。しかしその評価法, 訓練 法, 訓練期間が一定せず, 効果も報告者により異なっ

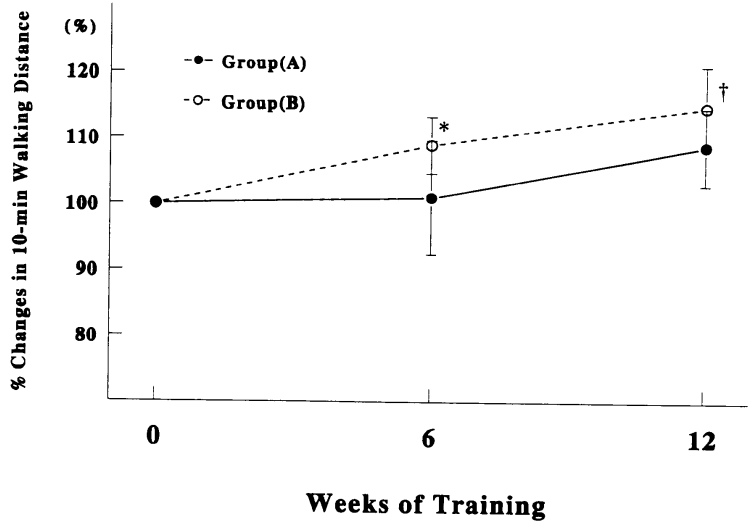

図３呼吸リハビリテーションによる10分間歩行距離 の変化率の推移を示す. A 群では前後で差を認めな かったが，B群では有意差を認めた. * $: p<0.05$ compared to baseline. $\dagger: \mathrm{p}<0.05$ compared to baseline.



図 $4 \Delta \mathrm{FRC}$ (functional residual capacity) と $\Delta \mathrm{RV}$ (residual volume) の相関関係学示す, $\Delta \mathrm{FRC}=$ (post-training FRC) - (pre-training FRC) ; $\Delta \mathrm{RV}=($ post-training $\mathrm{RV})-$ (pre-training $\mathrm{RV})$.

ていた。過換気呼吸により吸気筋訓練を施行した報 告 ${ }^{2)}$ では，運動耐容能が増加したものの呼吸筋力には 影響がみられなかった。COPDに対し初めて人工的な 器具を用いた報告3ではエルゴメーターにより運動耐 容能の増加を確認しているが, PImax は測定していな い. double-blind 法で吸気筋訓練の効果を検討した報 告 ${ }^{4)}$ では, PImax と呼吸筋の耐容能の指標である SIP (sustainable inspiratory pressure) はともに有意に増 加していた，吸気圧を視覚的にフィードバックできる 器具で訓練をした報告 ${ }^{5)}$ ではPImax と呼吸困難感の 改善がみられた。訓練期間も報告により 4 週 ${ }^{4}, 8$ 週3)5)6) と差を認めていた。 
しかし安静時の呼吸機能の変化は通常みられていな い. 今回の呼吸機能の検討の結果, $\mathrm{FRC}$ が呼吸法訓練 に吸気筋訓練を加えた群では訓練後低下していた。 FRC は最大の吸気筋である横隔膜の仕事量に影響を 与えており，COPDの換気効率，呼吸困難感を左右す るものである。その改善はどの因子による影響を受け ているかを検討したところ $\Delta \mathrm{FRC} は \Delta \mathrm{ERV}$ (予備呼気 量)よりも $\Delta \mathrm{RV}$ (残気量) の方に相関関係が得られた (図 4 ).つまり FRC の改善は FRVより RV の改善に 依っていると考えられた。このことは FRCの改善に は呼吸筋力の増加よりも気道閉塞の改善が影響を及ぼ している可能性を示している. COPDにおけるRVの 増大は, 肺弾性収縮力の減少により気道閉塞が高肺気 量で生じ, CV (closing volume) が増大することが大 きな要因である。呼吸訓練の結果, 低肺気量位での気 道閉塞が改善し, $\mathrm{CV}$ が減少した可能性がある. 今回 $\mathrm{CV}$ を測定していないので, 未梢気道の内腔狭窄やコ ンプライアンスの低下の改善の確認は今後の検討項目 の一つといえよう。しかし低肺気量位での末梢気道病 変の指標となるフロー・ボリュウム曲線上の $\dot{\mathrm{V}}_{50} / \dot{\mathrm{V}}_{25}$ はリハビリ前後で変化を認めなかった。一方 Vp が有 意に増加したという結果は, 気道閉塞の改善と呼吸筋 力の増強がともに関与している可能性を示唆してい る。

Larson らは吸気圧負荷の設定を最大吸気圧の $30 \%$ の方が効果があるとしている ${ }^{6}$ が，今回の対象例が COPD である上に高齢者であることを考虑し，抵抗圧 レベルを個々の症例の口腔内最大吸気圧（PImax）の 15\%に設定した。PImax は吸気筋訓練を混じえた A 群で増加していたが, その増加は呼吸筋力自体の増強 によるものなのか, リハビリによる最大の吸気筋であ る横隔膜の形状の変化によるものなのかを検討するた め, $\Delta \mathrm{PImax}$ と $\Delta \mathrm{FRC}$ の相関をみたが有意な関係は得 られなかった。つまり呼吸筋力自体の増強と考えられ る。

10 分間歩行距離測定は10分間にできるだけ速く歩い た距離で運動能力を評価する方法である. 主に運動耐 容能の評価指標として用いられている ${ }^{11)}$.しかし，その 値は呼吸機能以外に循環系の影響やまた心理的影響を うけることが知られている。 今回の検討では呼吸法に 吸気筋訓練を加えた A 群には訓練前後で変化を認め なかった。この事は Larson らの PImax の15\%の負荷 の吸気筋の訓練では歩行距離の改善が認められず30\% の負荷で, 改善がみられた報告到に矛盾しない結果で
あった。また，B群において10分間歩行距離に改善を 認めた点に関しては, A 群の平均年齢が B 群より高齢 の傾向があったこと，また歩行距離測定法が心理的要 因に左右され易( ${ }^{12) 13)}$ こ, 肺循環系の要因が影響し た可能性が推測される。

吸気筋訓練器の種類, 期間, 呼吸方法を変えて詳細 に検討した報告7では, 運動耐容能より呼吸筋力増強 の有用性を強調しているが，10分間歩行距離測定が運 動耐容能の評価指標としてどの程度信頼性があるかも 含め，今後の検討を要するものと思われた。

我及の以前の報告 ${ }^{14)}$ では12週の訓練中止にて， 6 週 間後, $\dot{\mathrm{V}} \mathrm{p}$, 呼吸筋力は低下し, FRC が増大する傾向を みた。また，未発表のデータであるが 36 週間以上の呼 吸筋訓練を含めた長期間の呼吸リハビリテーションを 受けた 5 症例においては，12週後より効果が認められ たが，12週以後は頭打ちとなり呼吸機能のさらなる改 善効果はなく, 維持効果のみを認めた.

今回の結果により，老年者の COPD 症例において も, 呼吸法訓練に定量的吸気負荷を加えた呼吸リハビ リにより 6 週間後から肺機能や呼吸筋力が改善するこ とが示された．そしてその効果の維持には，中断する ことなく12週以上継続する必要があるものと考えられ た. 今回の症例では運動能力の改善には直ちに反映さ れなかったが，吸気筋訓練のみならず，上肢・下肢の トレーニング，トレッドミル，ウォーキングを取り入 れた報告 ${ }^{8}$ や吸気負荷を 6 力月行った報告 ${ }^{9}$ もある.今 後, 訓練の持続期間, 方法, 精神心理学的サポートな どのケアも含めて，医師のみならず理学療法士などの スタッフや家族の協力も要する集学的医療のさらなる 検討が必要であると考えられた。

\section{文献}

1) Leith DE, Bradley $M$ : Ventilatory muscle strenth and endurance training. J Appl Physiol $1976 ; 41: 508-516$.

2) Belman $\mathrm{MJ}$, Mittman $\mathrm{C}$ : Ventilatory muscle training improves exercise capctity in chronic obstructive pulmonary disease patients. Am Rev Respir Dis 1980 ; 121 : 273-280.

3) Sonne LJ, Davis JA : Increased exercise performance in patients with severe COPD following inspiratory resistive training. Chest $1982 ; 81$ : 436-439.

4) Chen HI, Dukes R, Martin BJ: Inspiratory 
muscle training in patients with chronic obstructive pulmonary disease. Am Rev Respir Dis $1985 ; 131: 251-255$.

5) Harver A, Mahler DA, Daubenspeck JA : Targeted inspiratory muscle training improves respiratory muscle function and reduces dyspnea in patients with chronic obstructive pulmonary disease. Ann Intern Med 1989; 111 : $117-124$.

6) Lason JL, Kim MJ, Sharp JT, Larson DA : Inspiratory muscle training with a pressure threshold breathing device in patients with chronic obstructive pulmonary disease. Am Rev Respir Dis 1988 ; 138 : 689-696.

7) Belman MJ, Bothick WC, Nathan SD, Chon $\mathrm{KH}$ : Ventilatory load characteristics during ventilatory muscle training. Am J Respir Crit Care Med 1994 ; 149 : 925-929.

8) Goldstein RS, Gort EH, Stubbing D, Avendano MA, Guyatt GH : Randomised controlled trial of respiratory rehabilitation. Lancet $1994 ; 344$ : 1394-1397.

9) Weiner P, Azgad Y, Ganam R: Inspiratory muscle training combine with general exercise reconditioning in patients with COPD. Chest
$1992 ; 102: 1351-1356$.

10) Black LF, Hyatt RE: Maximal respiratory pressures: normal values and relationship to age and sex. Am Rev Respir Dis 1969 ; 99 : 696702.

11) Dekhuyzen PNR, Kaptein AA, Dekker FW, Wagenaar JPM, Janssen PJ: Twelve-minute walking test in a group of Dutch patients with chronic obstructive pulmonary disease: Relationship with functional capacity. Eur J Respir Dis 1986 ; 69(Suppl 146) : 259-264.

12) Morgan AD, Peck DF, Buchanan DR, McHardy CJR: Psychological factors contributing to disproportionate disability in chronic bronchitis. J Psychosom Res 1983 ; 27 : 259-263.

13）大津 格, 井上雅樹, 萩谷 政明, 富岡真一郎, 青 木弘道, 角昌 晃ほか: 肺気腫症例の呼吸リハビ リテーションにおける心理的変化の検討. 日胸疾 会誌 $1996 ; 34: 1337-1341$.

14）須藤英一, 四元秀毅, 大久保昭行, 福地義之助, 大 賀栄次郎, 松瀬 健ほか：COPDにおける吸気 筋・呼吸法訓練の肺機能及び呼吸困難への影響と その持続に関する検討. 厚生省特定疾患呼吸不全 調査研究班, 平成 6 度研究報告書, 1995, p133137. 
Abstract

\title{
The Effects of Pulmonary Rehabilitation Combined with Inspiratory Muscle Training on Pulmonary Function and Inspiratory Muscle Strength in Elderly Patients with Chronic Obstructive Pulmonary Disease
}

\author{
Eiichi Sudo ${ }^{1)}$, Eijiro Ohga ${ }^{1)}$, Takeshi Matsuse ${ }^{1)}$, Shinji Teramoto ${ }^{1)}$, \\ Takahide Nagase ${ }^{1)}$, Hirohumi Katayama ${ }^{2}$, Hajime Takizawa ${ }^{2}$, \\ Masanori Tanaka ${ }^{2)}$, Nobuko Kikuchi ${ }^{2)}$, Shuuichi Kakurai ${ }^{3)}$, \\ Yoshinosuku Fukuchi ${ }^{4)}$ and Yasuyoshi Ouchi ${ }^{1)}$
}

It has been suggested that pulmonary rehabilitation compined with inspiratory muscle training (IMT) might improve pulmonary function and respiratory muscle strength in elderly patients with chronic obstructive pulmonary disease (COPD). To test this hypothesis, inspiratory muscle strength (PImax), expiratory muscle strength (PEmax) and resting pulmonary function were measured in 13 elderly patients with COPD (aged $70.3 \pm 2.7$ years). Inspiratory muscle training (IMT) was performed for 15 min twice a day, using a pressure threshold device, for a total of 12 weeks. The inspiratory threshold was set at $15 \%$ of maximal inspiratory pressure (PImax) for each individual. Pulmonary rehabilitation was performed for 12 -h sessions over

1) Department of Geriatrics, Faculty of Medicine, University of Tokyo

2) Department of Laboratory Medicine, Faculty of Medicine, University of Tokyo

3) Division of Rehabilitation Service, Faculty of Medicine, University of Tokyo

4) Department of Respiratory Medicine, Juntendo University, Tokyo, Japan a 12-week period. Patients with COPD were assigned randomly to two groups: pulmonary rehabilitation combined with IMT (group A) $(\mathrm{n}=7)$, and conventional pulmonary rehabilitation only (group B) $(n=6)$. Functional residual capacity $($ FRC) decreased significantly from $4.3 \pm 0.4 \mathrm{~L}$ at baseline to $3.9 \pm 0.4 \mathrm{~L}$ after rehabilitation $(\mathrm{p}<0.01), \dot{\mathrm{V}} \mathrm{p}$ significantly increased from $4.6 \pm 0.8 \mathrm{~L} / \mathrm{sec}$ at baseline to $5.1 \pm 0.7 \mathrm{~L} / \mathrm{sec}$ after rehabilitation $(\mathrm{p}<$ $0.05)$ and the PImax increased significantly from $51.5 \pm 5.4 \mathrm{cmH}_{2} \mathrm{O}$ at baseline to $80.9 \pm 7.0 \mathrm{cmH}_{2}$ $\mathrm{O}$ after rehabilitation $(\mathrm{p}<0.02)$ in group $\mathrm{A}$. How ever, these variables did not change in group $B$. There was no improvement in the 10-minutes walking distance of group A, but there was a significant increase in that of group B. It can be concluded that pulmonary rehabilitation combined with IMT improves pulmonary function and inspiratory muscle strength in elderly patients with COPD.

Key words: Chronic obstructive pulmonary disease, Pulmonary rehabilitation, Inspiratory muscle train. ing (IMT), Maximal inspiratory pressure (PImax), Maximal expiratory pressure (PEmax), 10-minute walking distance

(Jpn J Geriat 1997; 34: 929-934.) 